\title{
A imprensa platina e a Missão Especial do Brasil ao Uruguai, abril de 1964
}

\author{
DINAIR ANDRADE DA SILVA*
}

\section{Introdução}

Vitorioso o movimento militar de 31 de março de $1964^{1}$, Goulart e seus principais auxiliares viajaram para o Uruguai, enquanto outros buscaram asilo diplomático nas várias embaixadas estrangeiras. O ex-Presidente desembarcou em Montevidéu no dia 4 de abril. ${ }^{2}$

Foi recebido por funcionários da Embaixada do Brasil, do Consulado Geral e do Serviço de Expansão e Propaganda Comercial, além de altas autoridades do Governo uruguaio, como o Subsecretário da Defesa Nacional, o Inspetor Geral da Força Aérea, o Chefe do Departamento Político e Diplomático do Ministério das Relações Exteriores, e, ainda, por dois Senadores da República. ${ }^{3}$

Goulart manifestou o propósito de asilar-se naquele país, no que foi seguido por diversos ex-colaboradores, que para lá se dirigiram em dias subseqüentes. ${ }^{4}$

No entanto, o Governo do Brasil, recém-instalado, temia que membros do Governo deposto, utilizando o território uruguaio como base de suas operações, viessem a subverter a nova ordem política brasileira e desassossegar a opinião pública com o objetivo de retomar o poder "até mesmo pelo emprego de meios violentos". ${ }^{5}$

No intuito de resguardar-se de eventual desmoralização, o Governo brasileiro enviou, em 13 de abril, uma Missão Especial ao Uruguai para negociar com as autoridades locais algumas medidas atinentes àquela situação. ${ }^{6}$ Na verdade, o ideal para os militares era que Goulart e seus simpatizantes deixassem o Continente americano. No entanto, seria aceitável ao Brasil o confinamento deles no Departamento de Montevidéu, preferencialmente, onde seriam mais facilmente monitorados por aquele Governo e estariam mais distantes da fronteira com o Brasil. ${ }^{7}$

Quanto a esta matéria, dois argumentos conexos fundamentavam a posição do Brasil. Por um lado, a intransigente defesa das tradicionais relações de amizade 
entre os dois países; por outro, a inflexível luta contra o surgimento de uma zona de fricção do âmbito da política interamericana. ${ }^{8}$

\section{Busca frustrada do confinamento impossível}

A Missão Especial desembarcou na capital uruguaia na tarde de 13 de abril e instalou-se nas dependências da Embaixada brasileira, conforme sugestão da Secretaria de Estado. ${ }^{9}$ Neste mesmo dia, já noite, ocorreu uma reunião, presidida pelo Enviado Especial, Ministro Jayme de Souza Gomes, em que estavam presentes o Chefe da Embaixada do Brasil, o Encarregado de Negócios, Ministro Júlio Agostinho de Oliveira, o Adido Militar, Major Fernando Valente Pamplona, ${ }^{10}$ os Secretários Guy Pinheiro de Vasconcellos e Gilberto Ferreira Martins. Uma vez inteirados do objetivo fundamental da Missão Especial, examinou-se, com o Encarregado de Negócios, a situação do pessoal da Embaixada. Nesse sentido, tomaram-se medidas tanto de natureza administrativa, requisitando pessoal para suprir as demandas do momento, ${ }^{11}$ quanto de natureza política, destituindo funcionários comprometidos ou supostamente comprometidos com o Governo deposto. ${ }^{12}$

Ainda no âmbito das providências mais imediatas, procedeu-se ao estudo dos textos legais referentes à questão, ou seja, a Convenção de Caracas de 1954, sobre Asilo Territorial, e o Decreto do Governo uruguaio, de 5 de julho de 1956, sobre Refugiados Políticos Estrangeiros. O estudo revelou, por antecipação, os resultados de uma difícil negociação que logo começaria. O Uruguai, não ratificando a Convenção de Caracas sobre Asilo Territorial, editou o Decreto de 5 de julho para regulamentar a questão no seu território. No Art. $2^{\circ}$ desse Decreto constava que "el domicilio o lugar de residencia que libremente fije el refugiado" deveria ser registrado no Ministério do Interior. Por outro lado, o texto de Caracas, não vigente no Uruguai, ao prever no seu Art. IX o internamento do asilado "em distância prudente de suas fronteiras”, é que atenderia às pretensões do Brasil. ${ }^{13}$

Vale ressaltar que, em 10 de abril, o Encarregado de Negócios da Embaixada em Montevidéu prestou esclarecimentos ao Ministro de Estado sobre a presença do ex-Presidente Goulart no país e as conseqüentes discussões nos meios políticos locais. Pelo que se depreende do texto, o diplomata apresentou à Secretaria de Estado um quadro relativamente promissor quanto à possibilidade de o Brasil conseguir das autoridades do Uruguai o confinamento dos brasileiros lá asilados. ${ }^{14}$

Havia a expectativa de que um respaldo militar seria necessário à concretização dos objetivos da Missão. Nessa ordem de idéias, o Major Pamplona manteve encontros reservados com comandantes militares uruguaios, nos dias 14 e 16 de abril. Naqueles encontros, fez uma explanação dos objetivos ${ }^{15}$ do movimento militar no Brasil, prestou informações sobre a situação política brasileira de então 
e manifestou as preocupações do Governo brasileiro com a permanência dos asilados na zona de fronteira. Ao mesmo tempo, conclamou aqueles oficiais, em nome das "Classes Armadas brasileiras", a prestarem o apoio e os esclarecimentos necessários junto ao Governo uruguaio, visando o sucesso da Missão Especial. ${ }^{16}$

Num país, à época, eminentemente civilista, onde os meios militares possuíam escassa influência na vida política, as gestões do Adido Militar da Embaixada do Brasil foram completamente inócuas, a despeito da receptividade que disse haver encontrado por parte das autoridades militares uruguaias. ${ }^{17}$

No dia 15 de abril, o Encarregado de Negócios, Ministro Júlio Agostinho de Oliveira, em Nota à Chancelaria uruguaia, comunicou a posse do Presidente Castelo Branco. ${ }^{18}$

O Emissário brasileiro foi recebido, em 17 de abril, pelo Presidente do Conselho Nacional de Governo, Luis Giannattasio, que estava acompanhado do Ministro de Estado das Relações Exteriores, Alejandro Zorrilla de San Martin, em encontro que se estendeu por cerca de duas horas. ${ }^{19}$ Naquela oportunidade, o Governo do Uruguai foi informado sobre o "caráter democrático" e a absoluta irreversibilidade do movimento militar de 31 de março. ${ }^{20}$ Foram também explicitadas as preocupações do Governo brasileiro com a presença, em território uruguaio, do ex-Presidente Goulart e de seus prosélitos, o que poderia redundar na subversão da ordem recém-instaurada no Brasil. ${ }^{21}$

O Uruguai, em razão dos seus reconhecidos sentimentos de humanidade, receberia, com certeza, aqueles brasileiros na condição de asilados territoriais. ${ }^{22}$ Nesse caso, enfatizava o Enviado Especial, o Governo do Presidente Castelo Branco encarecia o Governo Giannattasio que decretasse o confinamento dos asilados em região distante da fronteira com o Brasil. ${ }^{23}$

O Governo brasileiro considerava, também, como matéria de relevante interesse nacional que os asilados fossem "impedidos de conspirar contra a estabilidade política do atual Governo, de buscar impacto para seus planos conspiratórios através de entrevistas à imprensa nacional e estrangeira, declarações pelo rádio ou televisão, ou de outros meios eficazes". ${ }^{24}$

Com essas negociações buscava-se, no entendimento do Representante do Brasil, a preservação e a ampliação das relações amistosas e cordiais entre os dois países. Mais ainda, evitar possíveis atritos entre vizinhos, com a possibilidade de se criar uma zona de fricção, com graves prejuízos, não só para os dois Estados, mas também para o sistema interamericano como um todo. ${ }^{25}$

Foram aventadas três hipóteses com riscos de incidentes fronteiriços: 1) incursões de militares ou policiais brasileiros incontrolados, em território uruguaio, para deter asilados; ${ }^{26}$ 2) incursões de asilados no Uruguai, em território brasileiro, para praticar atos de sabotagem, terrorismo e guerrilha; ${ }^{27} 3$ ) militarização da fronteira, pelo Brasil, com sérios riscos de confronto entre tropas. ${ }^{28}$

O Negociador brasileiro, no seu propósito de convencer o Governo uruguaio das pretensões do Brasil, invocou, ainda, fatos da história das relações internacionais 
do Cone Sul da década anterior, para documentar que o Brasil esteve sempre ao lado do Uruguai. ${ }^{29}$ Em 1953, o Brasil apoiou o país vizinho quando do incidente, em Montevidéu, com o Adido Operário da Argentina. ${ }^{30}$ Nesta mesma linha de raciocínio, em 1955, o Brasil negou asilo político ao ex-Presidente argentino Juan Domingo Perón. ${ }^{31}$

Ao concluir estas ponderações, o Enviado do Governo brasileiro chegou mesmo a condicionar o confinamento solicitado à liberação dos salvo-condutos aos asilados diplomáticos brasileiros que se encontravam na Embaixada uruguaia no Rio de Janeiro. Nesse sentido, Souza Gomes dirigiu-se ao Ministro de Estado, em telegrama particular, datado de 17.04.64: "rogo com o máximo empenho ao querido amigo e chefe, não conceder salvo-conduto a nenhum asilado dos que se encontram em qualquer das Embaixadas estrangeiras, até a minha volta ao Rio, elemento decisivo para o êxito das negociações”. ${ }^{32}$ A resposta afirmativa chegou, seis dias depois, à Embaixada em Montevidéu: "fique tranqüilo quanto à solicitação que fez a respeito das pessoas asiladas na Embaixada uruguaia, pois que atenderei o seu pedido." ${ }^{33}$

O Presidente Luis Giannattasio manifestou compreensão pelas preocupações do Brasil em evitar atritos que pudessem colocar em risco as relações entre os dois Estados fronteiriços. No entanto, ao abordar o problema dos asilados diplomáticos na Embaixada uruguaia no Rio de Janeiro, foi enfático ao falar da "obrigatoriedade da concessão dos respectivos salvo-condutos, por parte do Governo brasileiro”, idéia que foi reforçada pelo Ministro das Relações Exteriores Alejandro Zorrilla de San Martin ali presente. ${ }^{34}$ O Enviado brasileiro, Ministro Souza Gomes, a seu turno, mencionou que o Uruguai se encontrava sujeito, nesse particular, à Convenção de Havana, de 1928, que não fixava prazo para a concessão de salvocondutos. $^{35}$

O Presidente do Conselho Nacional de Governo informou ao Ministro Souza Gomes que ao pleito do Brasil se antepunham algumas dificuldades. Inicialmente, comentou que o seu país não havia ratificado a Convenção de Caracas, de 1954, sobre a questão do Asilo Territorial e que a legislação uruguaia sobre o assunto era extremamente liberal. Por outro lado, na estrutura política colegiada, então vigente no Uruguai, as decisões emergiam da discussão e do voto dos membros do Conselho Nacional de Governo e não da vontade do seu Presidente. E, finalmente, havia outro dado relevante. A opinião pública e a imprensa nacional já haviam se posicionado contra os últimos acontecimentos políticos ocorridos no Brasil. Uma decisão do Governo, em sentido contrário, poderia colocar em risco a ordem pública bem como a estabilidade política do país. ${ }^{36}$

No que diz respeito à posição da imprensa brasileira face ao movimento militar de 31 de março, a opinião de Skidmore é no sentido de que “A Revolução de 1964 foi entusiasticamente festejada pela maior parte da mídia brasileira. Jornais importantes como o Jornal do Brasil, Correio da Manhã, O Globo, Folha de 
São Paulo, O Estado de São Paulo pugnavam abertamente pela deposição do governo Goulart”. ${ }^{37} \mathrm{O}$ único jornal de destaque que se opôs ao golpe foi a Última Hora, cujo diretor e fundador, Samuel Wainer, não teve outra opção senão a fuga. ${ }^{38}$ É importante esclarecer, no entanto, que a imprensa brasileira, de um modo geral, foi reorientando a sua posição diante ao golpe militar na medida em que os atos arbitrários, os expurgos e as torturas foram-se avolumando. ${ }^{39}$

O Emissário brasileiro queixou-se da imprensa uruguaia por não haver poupado nem ele, nem o próprio Presidente Castelo Branco. O Presidente do Conselho Nacional de Governo lamentou, comentando que ele próprio era uma vítima contumaz do periodismo do seu país. ${ }^{40}$

Após manifestar a sua compreensão a propósito das preocupações do Governo brasileiro no sentido de evitar qualquer risco sobre as relações entre os dois países, Giannattasio recordou ao Emissário brasileiro as convenções internacionais que obrigavam o Brasil a conceder os salvo-condutos aos asilados diplomáticos do Rio de Janeiro. ${ }^{41}$ Zorrilla de San Martin reiterou o tema da obrigatoriedade da concessão. Souza Gomes, a seu turno, assinalou a vigência, no Uruguai, da Convenção de Havana, de 1928, sobre Asilo Diplomático, que não fixava data para a expedição dos salvo-condutos. ${ }^{42}$

Ainda de posse da palavra, o Chanceler reiterou que a lei do seu país proporcionava ampla proteção aos asilados políticos e informou que o ex-Presidente Goulart já havia solicitado asilo territorial. ${ }^{43}$

A presença da Missão Especial em Montevidéu atiçou a imprensa uruguaia que, às vezes equivocada, via a busca do reconhecimento do novo Governo brasileiro como objetivo de Souza Gomes e da Missão que chefiava. O quadro retratado pelos veículos de comunicação era de muita tensão política. Giannattasio solicitou então, extra-oficialmente, ao Enviado Especial que deixasse, espontaneamente, o território uruguaio porque a sua presença, aos olhos da imprensa e da opinião pública, era um fator de pressão, indesejável e prejudicial a qualquer resultado acerca das reivindicações do Brasil. ${ }^{44}$

Sob intensas manifestações da imprensa no sentido de que o encontro entre o Enviado brasileiro e o Presidente do Conselho Nacional de Governo transcorrera num clima de muita rispidez, tensão e constrangimentos, Souza Gomes deixou Montevidéu na tarde de 19 de abril e dirigiu-se a Buenos Aires. ${ }^{45}$

A imprensa platina, em geral, insistia que o Ministro brasileiro viajava pelo Cone Sul em busca de reconhecimento para o novo Governo do Brasil. No entanto, o diplomata declarou, na Argentina, que lá estava para prestar informações verbais ao Embaixador Décio Moura sobre a situação política interna brasileira. ${ }^{46}$

Enquanto isso, no Uruguai, o Conselho de Governo, pelo Decreto de 21 de abril de 1964, declarava "asilado político al ciudadano brasileño Dr. João Belchior Marques Goulart”, que poderia fixar a sua residência em qualquer ponto do território nacional. ${ }^{47}$ 
Não se pode deixar de acentuar que a imprensa platina era favorável ao "janguismo". Desde a imprensa nitidamente comunista até os jornais de orientação conservadora, revelam idêntica linha de simpatia pelo ex-Presidente Goulart, ou por afinidade ideológica, ou por interesses econômicos comuns. ${ }^{48}$

Por outro lado, ressalta-se que a imprensa platina manifestou-se claramente contrária ao arbítrio que havia sido instalado no Brasil a partir de 31 de março. O movimento militar brasileiro foi apresentado à opinião pública local como um "golpe de gorilas”. Na verdade, pode-se documentar este ponto de vista por meio da intensa produção jornalística sobre a questão. ${ }^{49}$

Ressalta-se que os asilados territoriais brasileiros tiveram amplo acesso a todos os meios de divulgação. E foram sempre acusados pelo Governo brasileiro de deturpar os fatos ocorridos no Brasil..$^{50}$

\section{Obtenção (inesperada) do reconhecimento não-reivindicado}

Na reunião do Conselho de Governo, em 23 de abril, o Uruguai reconhecia o novo Governo brasileiro por meio de Nota dirigida ao Encarregado de Negócios da Embaixada brasileira. ${ }^{51}$

Ao retornar a Montevidéu, a Missão Especial contabilizava fracasso fragoroso e sucesso insosso. O fracasso fragoroso vinculava-se à concessão do asilo ao ex-Presidente Goulart ${ }^{52}$ e o sucesso insosso ligava-se à obtenção do reconhecimento do Governo Castelo Branco. ${ }^{53}$

O Uruguai reconheceu, a duras penas, o Governo militar do Brasil. No encontro entre o Enviado brasileiro e o Chanceler uruguaio, na manhã do dia 24 de abril, o Ministro de Estado reiterou, "repetidas vezes, as dificuldades em ser aprovado o reconhecimento pelo Conselho Nacional de Governo, o que só se verificou após debates acalorados e por escassa maioria”. ${ }^{54}$ Contudo, preservou sua legislação interna pertinente ao asilo territorial, não estabelecendo o confinamento dos brasileiros. ${ }^{55}$

Restava ao Brasil, desprovido de maiores argumentos e fundamentos de direito interamericano e diante do impasse colocado pela decisão uruguaia, insistir na procrastinação da liberação dos salvo-condutos aos asilados diplomáticos nas Embaixadas no Rio de Janeiro. ${ }^{56}$

Chama a atenção a habilidade com que o Chanceler uruguaio vai desconstruindo as pretensões do Brasil postas pela Missão Especial. Em 24 de abril, ao convocar o Enviado brasileiro para um encontro, o Chanceler Zorrilla de San Martin agradeceu a comunicação da posse do Presidente Castelo Branco, aludindo-se ao reconhecimento que se expressou de maneira verbal, apenas. Em seguida, o Ministro de Estado, supervalorizando o conteúdo da Missão Especial, considerou satisfeitas as pretensões do Governo brasileiro apresentadas pelo seu Ministro Plenipotenciário. ${ }^{57}$ 
Souza Gomes demonstrou seu desagrado ao Chanceler, reiterando que o interesse do Brasil prendia-se à questão do confinamento e não ao tema do reconhecimento. ${ }^{58} \mathrm{E}$ acrescentou: "dentre cerca de oitenta Estados com os quais o Brasil mantém relações, três apenas - México, Venezuela e Cuba - não tinham efetivado aquela medida”. E concluiu: "Por certo, o Uruguai não desejaria ser um dos últimos Estados a fazê-lo". 59

Ouviu do Ministro de Estado que o ex-Presidente Goulart, como qualquer asilado no Uruguai, poderia se deslocar livremente pelo território nacional e que, também como qualquer outro asilado, seria, de acordo com as leis do país, observado pelas autoridades competentes. Ouviu, ainda, do Ministro de Estado que o "janguismo" exercia enorme influência nos meios políticos uruguaios. ${ }^{60}$

Ao Chefe da Missão Especial foi sugerido, por aquela autoridade, que as negociações prosseguissem, a partir de então, no âmbito de Embaixada e Chancelaria. Neste sentido, nada mais caberia ao Brasil que assistir o transcorrer dos fatos para, em sendo o caso, retomar junto à Chancelaria uruguaia o prosseguimento das negociações ou mesmo solicitar providências contra a atuação dos asilados brasileiros. ${ }^{61}$

Talvez numa última tentativa de reversão ou alteração das decisões então tomadas, o Emissário brasileiro mencionou que a questão dos salvo-condutos seria examinada, oportunamente, pelo Governo brasileiro. Assegurou, no entanto, que seriam restringidas as possibilidades de brasileiros se asilarem no Uruguai, posto que os entendimentos entre os dois países não foram satisfatórios ao Governo do Brasil. $^{62}$

Ao final do encontro, o Chanceler Zorrilla de San Martin afirmou que, para se criar um ambiente propício ao entendimento entre os dois países e melhorar os resultados das negociações vindouras, seria do maior interesse que o Brasil se empenhasse na solução dos casos pendentes entre os dois Estados, tais como: 1) a construção da ponte sobre o rio Quaraim; 2) a dragagem da bacia da Lagoa Mirim; 3) a construção do aeroporto comum para atender às cidades fronteiriças de Rivera e Santana do Livramento; 4) a edificação do centro recreativo e esportivo entre as mencionadas cidades. ${ }^{63}$

Neste quadro de tensão permanente, a imprensa platina não só se posicionou claramente contra o golpe militar brasileiro, emprestando-lhe sempre feição desfavorável aos olhos da opinião pública, como também acusou duramente o Governo Castelo Branco de haver implantado, no Brasil, um clima insuportável de terror, violência e sangue. ${ }^{64}$

\section{Considerações finais}

Na contabilização dos ativos e passivos da Missão Especial ao Uruguai, prevaleceu o débito, ou seja, a não obtenção do confinamento do ex-Presidente 
Goulart no Departamento de Montevidéu, o que, em verdade, era o objetivo da Missão.

Por isso mesmo, o Ministro Souza Gomes supervalorizou o reconhecimento do novo Governo brasileiro, concedido após acalorados debates entre os membros do Conselho Nacional de Governo, com uma escassa margem de votos (cinco votos a três, sendo que, entre os cinco, dois foram dados com restrições), e sob o protesto de amplos setores da opinião pública uruguaia.

Foi ressaltado, também, como ponto positivo alcançado pela Missão Especial a possibilidade do prosseguimento das negociações entre os dois países.

Parece pertinente afirmar que o Governo uruguaio saiu vitorioso e fortalecido destas negociações pelo fato de haver resistido aos embates da diplomacia de alta pressão exercida pelo Brasil por intermédio da Missão Especial.

O Negociador brasileiro acreditava que os expoentes do "janguismo" Goulart e Brizola - teriam sido informados, extra-oficialmente, pelo Governo do Uruguai da inconveniência de suas permanências naquele país. Teriam sido aconselhados a viajar "espontaneamente" para a Europa.

Neste caso, estaria sendo aliviada a pressão exercida pelo Governo brasileiro sobre o uruguaio por meio da denominada "operação vinculada", ou seja, os asilados territoriais, no Uruguai, se estivessem em processo de abandono do país ou confinados em local distante da fronteira, estariam contribuindo para a aceleração de concessão de salvo-condutos a asilados diplomáticos no Rio de Janeiro.

Foi considerada como vitória da diplomacia brasileira a viagem do exPresidente Goulart à França, em maio de 1964, posto que representava a provável desarticulação do movimento de reação desde o Cone Sul. À inversa, pode-se também admitir que a mencionada viagem tenha representado uma manobra do Governo uruguaio no sentido de promover a liberação dos salvo-condutos para os asilados diplomáticos do Rio de Janeiro.

O Emissário brasileiro, no exercício das atividades que desenvolveu na chefia da Missão Especial, sentiu não haver encontrado unânime boa vontade por parte das altas autoridades uruguaias. Por outro lado, percebeu que a reconstrução da imagem do Governo brasileiro no Uruguai não se faria senão com muito esforço da Embaixada em Montevidéu, quando renovada e melhor aparelhada.

Outubro de 2002

\section{Notas}

1 Nas primeiras horas da manhã do dia 2 de abril, o senador Auro de Moura Andrade, Presidente do Senado Federal, convocou uma sessão extraordinária e, em seguida, declarou a vacância do cargo de Presidente da República, consumando, desta maneira, o golpe de Estado. Vide dentre outros, BANDEIRA, L. A. M. O Governo João Goulart: as lutas sociais no Brasil, 1961- 
1964. 3 $3^{\text {a }}$ ed., Rio de Janeiro: Civilização Brasileira, 1978, p. 183 e SKIDMORE, T. E. Brasil: de Castelo a Tancredo, 1964-1985. Rio de Janeiro: Paz e Terra, 1989, p. 46.

2 A revista O Cruzeiro, de 25.04.64, ao se referir à chegada do ex-Presidente Goulart ao Aeroporto Militar de Pando, mencionou que "apesar da revolução brasileira, queriam recebê-lo com honras de Chefe de Estado...” o que, afinal, não se concretizou. Vide também VICTOR, M. Cinco anos que abalaram o Brasil (de Jânio Quadros ao Marechal Castelo Branco). Rio de Janeiro: Civilização Brasileira, 1965, p. 533.

3 Relatório da Missão Especial ao Uruguai, v. I, p. 2; Relatório., v. II, doc. 1: Telegrama n ${ }^{\circ}$ 46, de 04.04.64, da Embaixada em Montevidéu para a Secretaria de Estado; O Cruzeiro, de 25.04.64.

4 Dentre tantos, Ivo de Magalhães, ex-Prefeito de Brasília, jovem, nome em ascensão dentro do PTB, partido liderado por Goulart, que chegou a Montevidéu a bordo de um avião militar paraguaio, cf. Acción, de 15.04.64, Revolución de los ricos, dice la esposa; Leonel Brizola, ex-Deputado Federal do PTB pela Guanabara, um dos líderes da resistência, cunhado do ex-Presidente, cf. La Mañana, de 07.05.64, Por Artigas entró Brizola al Uruguay. Recorda-se que Brizola havia sido eleito Deputado Federal em 1962 “com uma votação recorde” e que era considerado “exaltado porta-voz do nacionalismo radical”. Cf. SKIDMORE, T. E. op. cit., p. 42 e 21, respectivamente.

5 Relatório...,v. I, p. 2.

6 Dirigida por Jayme de Souza Gomes, Chefe do Departamento de Assuntos Jurídicos do Ministério das Relações Exteriores e integrada pelo Secretário Gilberto Ferreira Martins e a Oficial de Administração Ricardina Gonçalves Martins. Esta Missão Especial produziu, em 22 de maio de 1964, um Relatório, em três volumes, que foi utilizado como fonte primária na elaboração deste texto. Ao final do trabalho, fez-se uma breve descrição deste Relatório na seção intitulada Fontes.

7 Relatório..., v. I, p. 3.

8 Ibid., v. I, p. 3-4.

9 Relatório..., v. II, doc. 6: Telegrama [de 12.04.64], DA/DAM/DP, cifrado, secreto-urgentíssimo, da Secretaria de Estado para a Embaixada em Montevidéu.

10 Ibid., v. II, doc. 4: Carta de 11 de abril, dirigida ao Major Pamplona pelo Cel. Lauro Alves Pinto, Chefe da D/2 do Gabinete do Ministro da Guerra, solicitando fosse dada ao Ministro Souza Gomes “ampla cooperação em seu trabalho”.

11 Ibid., v. II, doc. 7: Telegrama n ${ }^{\circ}$ 59, de 14.04.64, da Embaixada em Montevidéu para a Secretaria de Estado; doc. 8: Telegrama n ${ }^{\circ}$ 50, de 17.04.64, da Secretaria de Estado para a Embaixada em Montevidéu, dando conta de que as todas solicitações de Souza Gomes foram atendidas.

12 Consta do Relatório..., v. II, a dispensa de três funcionários, documentada em telegramas expedidos pela Secretaria de Estado. Um para Embaixada em Montevidéu, de nº 46, em 13.04.64, doc. 9; dois para o SEPRO em Montevidéu, em 11.04.64 e 06.05.64, docs. 10 e 11, respectivamente. Ainda no v. II do Relatório..., doc. 5: Instruções ao Ministro Jayme de Souza Gomes em sua Missão ao Uruguai, em 11 de abril de 1964, p. 2, onde se assegura que nas Repartições brasileiras em Montevidéu - Embaixada, Consulado Geral e SEPRO - "há elementos simpáticos, em maior ou menor grau, ao ‘janguismo', a respeito dos quais todas as precauções podem ser insuficientes”.

13 Vide Relatório..., v. II, doc. 12: Ofício nº 129, de 10.04.64, da Embaixada em Montevidéu para a Secretaria de Estado, contendo, em anexo único, o texto do Decreto de 05.07.56, com sua exposição de motivos; doc. 13: texto da Convenção de Caracas de 1954 sobre Asilo Territorial. Ibid., v. II, doc. 12: Ofício n ${ }^{\circ}$ 129, de 10.04.64, da Embaixada em Montevidéu para a Secretaria de Estado. Após comentário circunstanciado, o diplomata opina que a concessão de asilo político ao ex-Presidente e seus colaboradores "parece ter entrado num compasso de espera, que representaria um retrocesso da posição inicial tomada pelas autoridades uruguaias, como que indicando maior reflexão sobre as possíveis repercussões no campo internacional de uma 
decisão apressada”. E no parágrafo seguinte concluiu: “Tudo leva a crer, contudo, que o Governo uruguaio manter-se-á fiel aos compromissos assumidos em conferências e tratados internacionais sobre asilo territorial, mas que, respeitando a tradição do direito de asilo entre países fronteiriços, recomende aos refugiados prudente afastamento da faixa de fronteira".

O Manifesto expedido em 30.03.64 pelo Chefe do Estado Maior do Exército, General Castelo Branco, explicitava dois objetivos fundamentais dos conspiradores: o primeiro, "frustrar o plano comunista de conquista do poder e defender as instituições militares”, o segundo, "restabelecer a ordem de modo que pudessem executar reformas legais". Apud SKIDMORE, T. E. op. cit. p. 45. Vide, também, VIZENTINI, P. F. A política externa do regime militar brasileiro: multilateralização, desenvolvimento e construção de uma potência média (19641985). Porto Alegre: Ed. da Universidade / UFRGS, 1998, p. 24.

16 Relatório..., v. II, doc. 15: Telegrama n ${ }^{\circ}$ 60, de 15.04.64, da Embaixada em Montevidéu para a Secretaria de Estado mencionando que, no dia 14 de abril, o Adido Militar entrevistou-se com o General Gilberto Pereira, Inspetor Geral do Exército. Comentou, ainda, o Encarregado de Negócios a chegada a Montevidéu do ex-Prefeito de Brasília, Ivo Magalhães. Fato que serviu de pretexto para um alerta às autoridades militares e policiais no sentido de intensificar a vigilância das fronteiras; doc. 16: Telegrama nº 65, de 16.04.64, da Embaixada em Montevidéu para a Secretaria de Estado dando conta que, no dia 16, ocorreram dois encontros: um, com o General César Borba, Chefe do Estado Maior do Exército e, outro, com o General José Luiz Ramagli, Diretor do Instituto Militar de Estudos Superiores.

17 Relatório..., v. I, p. 10-11.

18 Ibid., v. II, doc. 17: Telegrama n ${ }^{\circ}$ 61, de 15.04.64, da Embaixada em Montevidéu para a Secretaria de Estado.

19 Ibid., v. II, doc. 18: Telegrama n ${ }^{\circ}$ 63, de 15.04.64, da Embaixada em Montevidéu para a Secretaria de Estado. Na ocasião, como de costume, foram apresentadas as credenciais: Carta de Plenos Poderes, outorgada ao Emissário Especial pelo Presidente Castelo Branco, datada de 15 de abril de 1964 e endereçada ao Presidente do Conselho de Governo do Uruguai; Carta de Chancelaria, datada de 11 de abril de 1964, onde o Ministro de Estado Vasco T. Leitão da Cunha apresenta o Emissário brasileiro ao Ministro de Estado das Relações Exteriores do Uruguai. Relatório..., v. II: docs. 2 e 3.

Relatório..., v. I, p. 12; Relatório., v. II, doc. 5: Instruções..., p. 2.

Ibid., v. II, doc. 5: Instruções..., p. 2.

22 Para o Chefe da Missão Especial, o Uruguai era "um padrão em matéria de acolhimento aos estrangeiros em situação política delicada”. Relatório..., v. I, p, 13.

23 As Instruções ao Ministro Souza Gomes enfatizavam que a Missão Especial deveria obter do Governo uruguaio "de preferência por escrito, o compromisso de que o ex-Presidente Goulart e os demais asilados políticos brasileiros sejam confinados no Departamento de Montevidéu”. Caso este compromisso não pudesse ser assumido, "pediria que os brasileiros tivessem a sua residência fixada em áreas prudentemente distantes da fronteira brasileira”. Finalmente, reivindicava-se que o Governo uruguaio deveria "conceder passaportes para os asilados que desejem abandonar o território uruguaio com destino a outro Continente”. Relatório..., v. II, doc. 5: Instruções..., p. 1-2.

Relatório..., v. II, doc. 5: Instruções..., p. 2.

Ibid., v. II, doc. 5: Instruções..., p. 3.

Ibid., v. II, doc. 19: Telegrama nº 62, de 15.04.64, da Embaixada em Montevidéu para a Secretaria de Estado relata violação da fronteira uruguaia, na ponte do Jaguarão, noticiada pelo periódico de linha moderada mas favorável aos asilados brasileiro, El Diário, atribuída a seis soldados comandados por um sargento. No mesmo volume, doc. 20: Telegrama 64, de 16.04.64, da Embaixada em Montevidéu para a Secretaria de Estado informa que jornais comunistas enfatizam o mesmo incidente fronteiriço. Jornais uruguaios veicularam a questão com destaque: El Diário, 
15.04.64, Gorilas brasileños cruzaron la frontera buscando goularistas; Época, de 16.04.64, Violación de fronteras: desmentido; EI Debate, de 16.04.64, Incidente fronterizo se produjo em Rio Branco. Jornais brasileiros também se ocuparam do tema: Diário de Notícias, de 16.04.64, Uruguai nega a violação das suas fronteiras; Correio da Manhã, de 16.04.64, Fronteira uruguaia teria sido violada.

27 A propósito, o Relatório..., v. I, p. 13 comenta que diversas propriedades rurais, pertencentes a pessoas ligadas ao antigo Governo, estendem-se do território de um Estado para o do outro...” No vol. II, doc. 21: Mapa de la República Oriental del Uruguay, estão assinalados três pontos onde se localizariam as referidas propriedades rurais fronteiriças.

Relatório..., v. I, p. 3-4 explicita que a militarização de cerca de setecentos quilômetros de linha fronteiriça seria efetuada na medida em que se comprovasse a segunda hipótese mencionada. Ibid., v. I, p. 16.

Ibid., v. II, doc. 5: Instruções..., p. 3. Em decorrência de absurdas ameaças de ataque ao Uruguai por parte da Argentina, o Brasil, em resposta a uma consulta do Governo uruguaio, manifestou o seu apoio à República Oriental.

Ibid., v. II, doc. 5: Instruções..., p. 3-4. Em dois momentos foi negado a Perón asilo em território brasileiro: primeiro, quando ele deixava o seu asilo no Paraguai; posteriormente, o ex-Presidente argentino viu frustradas as suas pretensões de residir no Brasil.

Ibid., v. II, doc. 23: Telegrama s/n, de 17.04.64, da Embaixada em Montevidéu para a Secretaria de Estado.

Ibid., v. II, doc. 24: Telegrama n ${ }^{\circ}$ 57, de 23.04.64, da Secretaria de Estado para a Embaixada em Montevidéu.

34 Ibid., v. I, p. 18.

Ibid., v. II, doc. 29: Convenção de Havana, de 1928, sobre Asilo Diplomático, Art. $2^{\circ}$, § $3^{\circ}$.

Ibid., v. II, doc. 30: Telegrama n ${ }^{\circ}$ 67, de 17.04.64, da Embaixada em Montevidéu para a Secretaria de Estado contendo uma descrição circunstanciada do encontro entre o Enviado brasileiro e o Presidente do Conselho Nacional do Governo uruguaio, ocorrida em 17 de abril, especialmente, p. 5.

37 SKIDMORE, T. E. op. cit., p. 63. A grande imprensa brasileira, quanto a essa questão, foi examinada, minuciosamente, por STEPAN, A. The military in politics: changing patterns in Brazil. Princeton: Princeton University Press, 1971, p. 57-121.

39 ALVIM, Thereza Cesário (ed.). O golpe de 64: a imprensa disse não. Rio de Janeiro: Civilização Brasileira, 1979, onde se publicou uma coletânea de críticas à Revolução.

40 Relatório..., v. I, p. 17, onde o Enviado Especial comentou o ponto de vista do Presidente do Conselho Nacional do Governo uruguaio favorável a não subestimar a opinião pública local. Ainda com referência à opinião pública, mostrou a influência sobre ela exercida pela imprensa esquerdizante, sublinhando, inclusive, o risco do Governo uruguaio tornar-se alvo de impiedosa oposição, que, com certeza, provocaria desassossego à política interna.

41 Ibid., v. I, p. 17-18.

42 Ibid., v. II, doc. 29: Convenção de Havana, de 1928, sobre Asilo Diplomático, Art. $2^{\circ}$, § $3^{\circ}$.

43 Ibid., v. I, p. 18.

44 Ibid., v. I, p. 19.

45 Ibid., v. II, doc. 27: Telegrama n ${ }^{\circ}$ 139, de 19.04.64, da Embaixada em Buenos Aires para a Secretaria de Estado. A repercussão na imprensa platina e brasileira foi significativa. Senão vejamos.: Acción, de 16.04.64, Emisario brasileño; El Diario, de 16.04.64, Emisario brasileño; El Plata, de 16.04.64, Está en Montevideo el enviado personal del presidente de Brasil; El Diario, de 17.04.64, Emisario de Castelo Branco visitó la Casa de Gobierno; El Plata, de 17.04.64, Fue recibido hoy el Enviado de Brasil; Diário Carioca, de 17.04.64, Brasil pede a 
Uruguai que reconheça Castelo; EI Diario, 17.04.64, Gestiona reconocimiento del Gobierno de Uruguay; O Jornal, de 17.04.64, Brasil não quer Goulart perto de suas fronteiras; Tribuna, de 17.04.64, Governo exige que Jango saia da América do Sul; Jornal do Brasil, de 17.04.64, Itamarati manda estudar situação de Goulart junto ao Governo uruguaio; O Globo, de 17.04.64, O Brasil não quer Goulart perto de suas fronteiras; La Nación, 19.04.64, Gestiones en el Uruguay de un enviado brasileño; El Clarin, de 20.04.64, Uruguay: logró escaso éxito en su misión el Enviado brasileño; Diário Carioca, de 19.04.64, Uruguai: nada decidido sobre o reconhecimento; Jornal do Commercio, de 19.04.64, Uruguai ainda não reconheceu; Diário Carioca, 21.04.64, Uruguai: atuação de enviado dificultou mais reconhecimento; La Mañana, de 18.04.64, Fueron escuchados los planteos del emisario brasileño, Dr. Souza Gomes; El Dia, de 18.04.64, El gobierno uruguayo y la situación en Brasil; Acción, de 18.04.64, Preocupa a Brasil la presencia de J. Goulart en Uruguay; Tribuna da Imprensa, [de 18.04.64], Itamarati insiste na transferência de JG para país europeu; O Globo, de 18.04.64, O não-reconhecimento do atual governo obriga a ida de enviado ao Uruguai; Época, de 18.04.64, El emisario gorila.

Ibid., v. II, doc. 31: Decreto de 21 de abril de 1964, que declara asilado político o cidadão brasileiro João Belchior Marques Goulart. Esta decisão teve como base o preceito do Art. $1^{\circ}$ do Decreto de 5 de julho de 1956: "Se considerará refugiado político a todo estrangero residente a cualquier título en la República, por motivos derivados de una persecusión política presumiblemente cierta”.; doc. 31: Telegrama nº 71, de 22.04.64, da Embaixada em Montevidéu para a Secretaria de Estado; O Decreto de 21 de abril repercutiu na imprensa: Última hora, de 22.04.64, Como refugiado JG não terá no Uruguai limitações de asilado; El Clarín, de 22.04.64, Goulart, asilado; La Prensa, de 22.04.64, Otorgaron a Goulart asilo en Uruguay; La Nación, de 22,04.64, João Goulart es asilado político en el Uruguay; Acción, de 22.04.64, Goulart, asilado político; El Diario, de 22.04.64, Goulart fue declarado refugiado político; EI Plata, de 22.04.64, El Consejo declaró exilado político al ciudadano brasileño Joao Goulart; Diário Carioca, de 23.04.64, Uruguai dá a Jango condição oficial de asilado; La Mañana, de 23.04.64, Joao Goulart continuará residiendo en el Uruguay; Correio da Manhã, de 23.04.64, Oficializado asilo político de Jango.

Ibid., v. I, p. 36.

49 Dentre outros: Acción, de 15.04.64, Revolución de los ricos, dice la esposa; Acción, de 15.04.64, Las estructuras pesan todavía demasiado, Época, de 16.04.64, Brasil: más cesantías en el ejército; El Popular, de 16.04.64, EE. UU. paga y pone en marcha una ola de golpes en América; Marcha, de 17.04.64, Sólo las reformas de base darán paz al Brasil; El Debate, de 18.04.64, Se encuentra ya en un callejón sin salida la dictadura del Brasil; El Debate, de 20.04.64, El derecho de asilo es sagrado; El mundo, de 20.04.64, Verdadera historia de la revolución brasileña; El Debate, de 21.04.64, Si los acontecimientos derivaran en una dictadura de fuerza no habría de prestarle mi cooperación; Época, de 23.04.64, Brasil: proceso del golpe gorila; Época, de 23.04.64, Brasil: los gorilas buscan a Juliao; El Popular, de 24.04.64, El pueblo repudia el gorilazo; El Popular, de 24.04.64, La intervención norteamericana en la crisis brasileña.

50 Relatório..., v. I, p. 36-37. Além de farto material produzido pela imprensa: El Diario, de 23.04.64, También era esperado el diputado Leonel Brizola; El Plata, 23.04.64, Último momento; El País, de 23.04.64, Buscan a Brizola; El Diario, 24.04.64, Mientras espera a su marido la señora de Brizola no habla; El Popular, de 24.04.64, Brizola estaría en Uruguay; EI Debate, de 24.04.64, Llegaron la sra. de Brizola y sus hijos; Época, de 25.04.64, Brasil: aumenta la represión; El Día, de 25.04.64, Podría ser inminente el arribo de Brizola; El Día, de 25.04.64, Brasil: buscan localizar radio clandestina de Leonel Brizola; El Día, de 26.04.64, Señora de Brizola: confío en que mi esposo esté en Uruguay.

51 Ibid., v. II, doc. 33: Telegrama ${ }^{\circ}$ 141, de 21.04.64, da Embaixada em Buenos Aires para a Secretaria de Estado: comunica que a questão do reconhecimento do Governo brasileiro consta 
da pauta da sessão plenária do Conselho Nacional de Governo a se realizar no dia 23 de abril; doc. 34: Telegrama $n^{\circ} 79$, de 25.04.64, da Embaixada em Montevidéu para a Secretaria de Estado dá conta de que o Ministro Zorrilla tomou conhecimento da Nota Verbal nº 97, de 15.04.64, da Embaixada brasileira, que faz saber ao Ministro das Relações Exteriores do Uruguai que o General Castelo Branco tomou posse como Presidente da República do Brasil; doc. 35: Telegrama $\mathrm{n}^{\circ}$ 81, de 24.04.64, da Embaixada em Montevidéu para a Secretaria de Estado.

52 O asilo não só foi concedido, mas concedido de acordo com o Decreto de 5 de julho de 1956, que permitia ao asilado tanto a livre circulação pelo território nacional quanto a fixação em qualquer ponto do mesmo. Ocorreu, na verdade, o que os militares mais temiam. E impedir este desfecho era, exatamente, o objetivo fundamental da Missão de Souza Gomes.

53 A Missão Especial ao Uruguai não possuía nenhuma instrução para negociar o reconhecimento do Governo brasileiro com as autoridades uruguaias.

54 Relatório..., v. I, p. 23; v. II, doc. 35: Telegrama n ${ }^{\circ}$ 81, de 24.04.64, da Embaixada em Montevidéu para a Secretaria de Estado, cujo teor é o seguinte: “...na votação do reconhecimento, os votos favoráveis, no total de cinco, foram todos de conselheiros da Maioria. Conselheiro Fernández Crespo votou a favor com reservas e o Conselheiro Lorenzo y Lozada apresentou fundamentação de voto. Esteve ausente, por enfermidade, Conselheiro Héber, também da Maioria. Votos contrários foram dos Conselheiros Gestido, Abdala e Vasconcello da Minoria.” Recorda-se que o Conselho era constituído, então, por nove membros.

55 Ao ser indagado, uma vez mais, pelo Enviado brasileiro a propósito do asilo concedido ao exPresidente Goulart, na forma do Decreto de 5 de julho de 1956, O Ministro das Relações Exteriores respondeu que outra não poderia ter sido a iniciativa do Governo uruguaio, que apenas aplicara disposições de sua legislação interna. Relatório..., v. I, p. 24.

56 Quanto a esta questão, Souza Gomes utilizou o mesmo argumento das autoridades uruguaias. No encontro com Zorrilla de San Martin, sustentou que, estando o Uruguai, então, sob os ditames da Convenção de Havana, de 1928, sobre Asilo Territorial, não poderia fazer qualquer reivindicação sobre prazos para liberação dos salvo-condutos aos asilados diplomáticos da Embaixada uruguaia no Rio de Janeiro, posto que aquele instrumento normativo, nesse particular, nada dizia nem sobre o prazo para concessão dos salvo-condutos e nem sobre a qualificação do delito motivador do asilo. Relatório..., v. I, p. 26.

57 Relatório..., v. I, p. 23.

58 Para demonstrar que as pretensões do Brasil não foram atendidas, agradeceu a entrega da Nota uruguaia alusiva ao reconhecimento que, imediatamente, passou às mãos do Encarregado de Negócios, com o intuito de deixar claro que a sua Missão não visava a obtenção da medida em apreço.Relatório..., v. I, p. 23.

59 Relatório..., v. I, p. 23.

60 Ibid., v. I, p. 25.

61 Ibid., v. I, p. 25-26.

62 Por diversas vezes, Souza Gomes reiterou a idéia de adiar, até o seu retorno ao Rio de Janeiro, a concessão dos salvo-condutos, vista por ele como uma forte moeda de negociação. Na verdade, tal medida não produziu os efeitos desejados.

63 Relatório..., v. II, doc. 40: Telegrama s/n, de 24.04.64, da Embaixada em Montevidéu para a Secretaria de Estado, p. 4.

64 A imprensa uruguaia deu ampla cobertura aos acontecimentos políticos que se desenrolaram no Brasil a partir do golpe militar de 31 de março, sempre hostilizando os militares. Denunciou, com veemência, a repressão odiosa refletida nas prisões, torturas e execuções de líderes sindicais e estudantis, organizadores de grupos católicos como a JUC (Juventude Universitária Católica) e AP (Ação Popular), organizadores de sindicatos e ligas camponesas. Foram destacados, dentre os colaboradores civis da repressão, os então governadores de Minas Gerais (Magalhães Pinto), de São Paulo (Adhemar de Barros) e da Guanabara (Carlos Lacerda). Para documentar 
este ponto de vista, citam-se, dentre outras, as seguintes manchetes: Denuncian prisión de un maestro en Brasil, El Diario, de 24.04.64; Brasil: encarnizada persecución a dirigentes del P. C., El Popular, de 24.04.64; Escritores del Uruguay contra las torturas en Brasil, Época, de 23.04.64; Planean asesinar a Arraes. Más de 10 mil presos por la dictadura, El Popular, de 16.04.64; Torturan a los presos políticos, El Popular, de 23.04.64; Terror en nombre de la democracia, Época, de 18.04.64.

\section{Fontes}

Relatório do Enviado Extraordinário e Ministro Plenipotenciário em Missão Especial junto ao Governo da República Oriental do Uruguai, Jayme de Souza Gomes, de 22 de maio de 1964, 3 volumes.

Vol. I: Histórico. Descrição circunstanciada da Missão Especial, que teve a duração de 13 a 30 de abril, com quarenta e três páginas, incluindo vinte seções específicas. Material classificado como secreto.

Vol. II: Documentação. Reúne cinqüenta e oito documentos oficiais, de caráter secreto, com a seguinte tipologia: telegramas recebidos e expedidos (material mais numeroso), cartas, instruções, ofícios, despachos, notas, textos legais, mapa do Uruguai etc.

Vol. III: Repercussão na Imprensa. Estão incluídos cento e noventa e três recortes de vinte e seis periódicos (doze brasileiros, oito uruguaios e seis argentinos), que refletem os desdobramentos da crise no Brasil e, principalmente, os embates da Missão Especial no Uruguai.

\section{Bibliografia}

ALVES, M. H. M. Estado e oposição no Brasil, 1964-1984. Petrópolis: Vozes, 1984.

ALVIM, T. C. (ed.). O golpe de 64: a imprensa disse não. Rio de Janeiro: Civilização Brasileira, 1979.

BANDEIRA, L. A. M. Brasil - Estados Unidos: a rivalidade emergente (1950-1988). Rio de Janeiro: Civilização Brasileira, 1989.

BANDEIRA, L. A. M. O Governo João Goulart: as lutas sociais no Brasil, 1961-1964. $3^{\text {a }}$ ed., Rio de Janeiro: Civilização Brasileira, 1978.

BENEVIDES, M. V. de M. A UDN e o udenismo: ambigüidades do liberalismo brasileiro, 19451965. Rio de Janeiro: Paz e Terra, 1981.

CERVO, A. L. Relações internacionais da América Latina: velhos e novos paradigmas. Brasília: IBRI, 2001.

CERVO, A. L.; BUENO, C. História da política exterior do Brasil. 2ª ed., Brasília: Editora Universidade de Brasília, 2002.

CORREA, M. S. 1964 visto e comentado pela Casa Branca. Porto Alegre: L \& PM, 1977.

DINES, A. et. alii. Os idos de março e a queda em abril. Rio de Janeiro: José Álvaro, 1964.

FIGUEIREDO, M. F. Política de coerção no sistema político brasileiro. Rio de Janeiro: Comissão de Justiça e Paz, 1978.

HIPPOLITO, L. De raposas a reformistas: o PSD e a experiência democrática brasileira, 19451964. Rio de Janeiro: Paz e Terra, 1985.

JUREMA, A. de A. Sexta feira 13: os últimos dias do Governo João Goulart. Rio de Janeiro: Edições O Cruzeiro, 1964. 
MOREL, E. O golpe começou em Washington. São Paulo: Brasiliense, 1965.

SANTOS, W. G. dos. Sessenta e quatro: anatomia da crise. São Paulo: Vértice, 1986.

SKIDMORE, T. E. Brasil: de Castelo a Tancredo, 1964-1985. Rio de Janeiro: Paz e Terra,1989.

STEPAN, A. The military in politics: changing patterns in Brazil. Princeton: Princeton University Press, 1971.

VIANA FILHO, L. O governo Castelo Branco. Rio de Janeiro: José Olympio, 1975.

VICTOR, M. Cinco anos que abalaram o Brasil (de Jânio Quadros ao Marechal Castelo Branco). Rio de Janeiro: Civilização Brasileira, 1965.

VIZENTINI, P. F. A política externa do regime militar brasileiro: multilateralização, desenvolvimento e construção de uma potência média (1964-1985). Porto Alegre: Ed. da Universidade / UFRGS, 1998.

\section{Resumo}

A imprensa platina em geral, e a uruguaia particularmente, adotou uma postura hostil ao movimento militar de 31 de março de 1964 no Brasil, conferindolhe o perfil de "golpe de gorilas", diante da opinião pública da região.

Nesse sentido, a atuação da imprensa tornou-se mais explícita quando desembarcaram em Montevidéu, no mês de abril daquele ano, os integrantes da Missão Especial do Brasil ao Uruguai. Pretendia-se, sob forte pressão, obter do governo uruguaio o compromisso formal de que o ex-Presidente Goulart e seus acompanhantes fossem confinados em área distante da fronteira brasileira, no Departamento de Montevidéu, onde poderiam ter suas atividades controladas, com maior facilidade, pelas autoridades uruguaias.

Diante da negativa da República vizinha, a Missão retornou, trazendo, curiosamente, o que não fora buscar, isto é, o reconhecimento do novo Governo do Brasil, obtido por estreita margem de votos do Conselho Nacional de Governo e sob forte oposição da imprensa e da opinião pública uruguaias.

\section{Abstract}

The press of the River Plate region, especially of Uruguay, showed a hostile attitude against the Brazilian military movement of March 31, 1964, depicting it to the public as a "gorilla coup".

This reaction became more explicit in April as the members of the Brazilian Especial Mission to Uruguay landed in Montevideo. The Mission's aim was to obtain from the Uruguayan Government, through the exertion of strong pressure, the formal compromise of confining former president Goulart and his companions to a distant area from the Brazilian border, namely the Montevideo Department, in which it would be easier for the Uruguayan authorities to keep their activities under control. 
Confronted with the neighboring Republic's refusal to attend its demand, the Mission returned to Brazil, but, curiously enough, taking home what it was not looking for: the recognition of the new Government, which was obtained from the National Council of Government by a scant majority of votes and under strong opposition on the part of the Uruguayan press and public opinion.

Palavras-chave: Missão ao Uruguai; Imprensa Platina; Ex-Presidente Goulart; Asilo Territorial e Confinamento; Reconhecimento do Governo Militar.

Key-words: Mission to Uruguay; Press of the River Plate Region; Former President Goulart; Territorial Asylum and Confinement; Recognition of the Military Government. 